\title{
Intersectoral governance for health in all policies - structures, actions and experiences*
}

\author{
David V. McQueen, Matthias Wismar, Vivian Lin, Catherine \\ M. Jones, Maggie Davies (editores), WHO/ European \\ Observatory on Health System and Policies, 2012
}

Resenha por: Amélia Cohn**

Esta publicação envolve vários pesquisadores que fazem parte do European Observatory on Health Systems and Policies. O título já é sugestivo: ao falar em governança intersetorial, não da, mas para a presença da saúde em todas as políticas para que se produza a intersetorialidade, já se tem o objetivo maior do estudo, que consiste na defesa da intersetorialidade da saúde por meio de sua presença em todas as políticas setoriais da área social.

Isso não é pouca coisa. Seja pelo objetivo em si, seja pela forma com que o livro foi organizado. Sua lógica de organização é exemplar: há dois capítulos introdutórios que tratam de forma substantiva a questão dos determinantes sociais da saúde e a governança, e de como as estruturas de governança podem detonar ações a favor da saúde em todas as políticas. A segunda parte é composta de análises de governança intersetorial a partir de experiências de vários países e que envolvem desde gabinetes de alto escalão até a administração conjunta de fundos para as políticas e o envolvimento do que denominam de "público" para que as ações de governo contribuam para a implantação da Hiap (Health in All Policies).

O capítulo 1, dedicado aos determinantes sociais da saúde e governança, rastreia a história do conceito, a partir do século XIX europeu, e aponta que o conceito tem origem fundamentalmente baseado na epistemologia epidemiológica, levando a uma concepção fortemente calcada não só na perspectiva médica, mas numa relação causal de via única. Quanto ao termo social, é mostrado como ele apresenta vários sentidos, que no geral envolvem a sociedade e as interações entre indivíduos e grupos na produção do bem-estar da sociedade

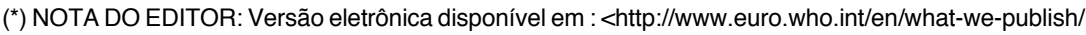
abstracts/intersectoral-governance-for-health-in-all-policies.-structures,-actions-and-experiences>. $\left.{ }^{(*}\right)$ Professora, Programa de Pós-Graduação em Saúde Coletiva, Católica Unisantos (Unisantos). Professora aposentada, Universidade de São Paulo. São Paulo/SP - Brasil.

Texto recebido em: 18/04/2013. Aprovado em 26/04/2013.

R. Dir. sanit., São Paulo, v. 14, n. 1, p. 264-267, mar./jun. 2013 
como um todo. E segue: no século $X X$, o termo social passa a ser discutido em termos de fatores de risco comportamentais que favorecem a doença. Segundo os autores, editores da publicação, essa tendência ainda continua, uma vez que em boa parte da literatura contemporânea sobre o tema o social continua referido à noção de um ranking ou de um status individual dos membros da sociedade. Outra dimensão destacada quanto aos determinantes sociais da saúde (DSS) diz respeito ao fato de que com frequência eles são referidos como fatores, talvez porque, segundo os autores, essa palavra seja mais operacional na compreensão e intervenção sobre a realidade por facilitar uma contribuição ativa de um elemento numa realidade complexa.

Da mesma forma, a utilização de da saúde e não na saúde implicaria uma causalidade mais difusa no argumento dos DSS. Complementarmente, a palavra saúde estaria revelando que o foco é muito mais sobre doença que sobre saúde, pois ela estaria significando ainda a presença da raiz do modelo médico e não um modelo social da saúde. No entanto, ressaltam os editores, a noção central no que se entende hoje na discussão sobre os DSS é a existência de um gradiente em que a variação na saúde pode ser representada graficamente numa curva. A evidência disso recai sobre o fato de que vários países obervaram disparidades na saúde, geralmente referidas a alguma noção de classe social, ao mesmo tempo em que entre vários países são observadas diferenças.

Quanto ao termo governança, ele é antigo, mas não no caso dos estudos e das políticas de saúde. Para os editores, governança é central para se conquistar um mundo mais saudável. Primeiro, porque governança envolve agentes do governo, sociedade civil e organizações não governamentais. O que não os deixa fugir de uma questão candente: que os estudiosos e agentes de governo que seguem o paradigma tanto da Hiap quanto dos DSS no geral colocam a saúde como o critério central para conduzir e avaliar o sucesso da ação estatal, e o fazem de forma explícita.

Por outro lado, no final do século passado e no início do presente verifica-se um deslocamento no discurso das políticas públicas do termo governo para governança. Isso não é apenas uma mudança na forma de se operacionalizarem as políticas públicas. Mas, como ressalta o texto, expressa o advento do gerencialismo (managerialism) e da ideologia neoliberal no interior dos governos. Daí o contraponto entre ambos, pois governança remete a um conceito e a uma prática mais inclusiva, envolvendo várias dimensões dos processos de tomada de decisões e de implementação das políticas. Para fins da pesquisa e da análise que se apresentam na publicação, governança envolve duas dimensões centrais: as estruturas que colocam os atores juntos; e as deliberações e ações que derivam dos engajamentos mútuos entre esses sujeitos.

Já no segundo capítulo a preocupação dos editores é outra: deslindar de que forma a Hiap se configura como uma nova prática, mais inclusiva, construindo práticas de colaboração intersetorial e das políticas públicas de saúde, mas focalizadas na ação da esfera pública de forma mais sistemática do que aquelas 
focalizadas somente nos objetivos da saúde. Isso porque a governança, defendem os editores, provê mecanismos de ação em prol da Hiap e dos DSS. E o capítulo vai então apresentar uma síntese das experiências de como distintas estruturas de governança podem estimular ações para tanto. E a partir daí são apresentados os resultados analíticos dos fatores que favorecem a governança em prol da Hiap e dos DSS trazidos pelos estudos de caso, componentes da parte 2 do livro.

Dentre eles estão, no nível governamental, comissões de gabinete e secretarias (ministérios); o parlamento (comissões parlamentares); o nível burocrático dos serviços civis; a administração dos fundos (orçamento único ou financiamento delegado) e o engajamento da sociedade no governo: público (sociedade civil); interessados (stakeholders); a participação de representantes da indústria, e as conferências de saúde. A seguir são apresentados os fatores favoráveis da participação de cada um desses segmentos na dinâmica do processo de governança pró Hiap e DSS.

Já a segunda parte do livro traz os estudos de caso (nove ao todo). Eles abrangem cada um dos eixos referidos e foram realizados em países tão diferentes quanto Nova Zelândia, Irlanda, Escócia e Austrália; Inglaterra, Estônia, Estados Unidos, Tailândia e Alemanha. Cada análise é muito bem feita, o levantamento dos dados bem realizado, e contém uma bibliografia final das mais ricas. Mas, mais do que isso, os estudos são coerentes com o quadro teórico-conceitual da equipe central, já que seus autores não são o grupo que edita a publicação. Nesse sentido, mais um ponto a favor da qualidade da publicação: a consistência entre a parte conceitual e os estudos de caso realizados.

Mas qual a questão central sobre uma publicação dessa natureza? Ela reside em algo que já é demonstrado na forma pela qual os estudos de caso são montados: a dificuldade de se identificar onde (países, regiões de países ou instituições internacionais) esses estudos foram realizados. Só se debruçando muito atentamente sobre o texto sabe-se onde foram realizados. Pode ser esse um truque dos autores: chamar a atenção mais para o objetivo central do trabalho, e portanto da publicação, e que consiste em isolar determinados eixos (anteriormente mencionados) e assim destacá-los como fatores importantes em prol da Hiap e dos DSS no interior das políticas públicas. Mas com isso perde-se a especificidade histórica de cada uma das realidades estudadas, e que definem se um determinado fator, positivo numa realidade, pode se revelar negativo em outra. Enfim, perde-se a historicidade da governança. Exemplo mais óbvio: o parlamento não é o mesmo nos regimes parlamentares de governo; não só em termos de sua composição, mas sobretudo do seu peso efetivo na definição e implementação das políticas públicas. O mesmo, para se referir a algo caro à realidade brasileira, ocorre com o federalismo e a cooperação entre esferas de governo.

Este estudo, mais uma vez reafimada sua consistência, traz um roteiro útil para 
se aproximar das distintas realidades da perspectiva da governança tendo como alvo a Hiap e os DSS. Até pela sua riqueza da parte conceitual e dos estudos de caso, extremamente consistentes. No entanto, é insuficiente para nos aproximarmos de realidades históricas concretas, sob pena de novos estudos sobre o tema ficarem limitados à perspectiva procedimental dos processos de tomada de decisões em detrimento das suas especificidades históricas em que esses processos ocorrem. Como por exemplo a força econômica e política do segmento privado, sendo este da saúde ou não, o que incide diretamente no perfil das parcerias público/privado (PPPs).

Até porque duas questões fundamentais acabam sendo subsumidas por esse tipo de análise aqui proposta: não há resposta (e adotada a perspectiva de análise presente nem poderia haver) sobre em que instância de governo devem se localizar a intersetorialidade e a integração entre as distintas políticas, no sentido de onde deve se localizar a integração delas em prol da Hiap e dos DSS como cabeça do processo de uma nova governança para a saúde. E segundo, qual o lugar da saúde no interior das políticas públicas: ela deve ser central e impor sua lógica às demais políticas setoriais, ou como ela se revela uma parceira no interior desse conjunto? Ou, dito de outro modo: os DSS devem ser a diretriz das políticas sociais ou os determinantes sociais das condições de vida e saúde é que devem sê-lo?

Essas questões remetem a algo mais amplo do que os propósitos explícitos do estudo realizado pelos editores e demais autores. No entanto, não são pouco relevantes para a compreensão da complexidade da realidade brasileira e a proposição de novas formas de integração e de intersetorialidade das políticas sociais e de saúde no país. Talvez a referência central em prol da Hiap e dos DSS devesse ser exatamente o combate às desigualdades sociais e a construção de maior justiça social. Embora fora do âmbito deste estudo, certamente é uma boa perspectiva para melhor aproveitá-lo perante os desafios das sociedades semiperiféricas como a nossa. 